\title{
Thyroid Pathology of Cypermethrin and Its Reproductive Implications in Yankasa Rams
}

\author{
Ubah Simon Azubuike ${ }^{1, ~ *, ~ O g w u ~ D a v i d ~}{ }^{2}$, Rekwot Peter Ibrahim², Rwuaan Joseph Sankey ${ }^{2}$, \\ Chibuogwu Ijeoma Chika ${ }^{3}$, Sambo Sohnap James ${ }^{4}$ \\ ${ }^{1}$ Department of Theriogenology, Faculty of Veterinary Medicine, University of Abuja, Federal Capital Territory, Nigeria \\ ${ }^{2}$ Department of Theriogenology and Production, Faculty of Veterinary Medicine, Ahmadu Bello University Zaria, Kaduna, Nigeria \\ ${ }^{3}$ Animal Science Department, Faculty of Agriculture, University of Abuja, Federal Capital Territory, Nigeria \\ ${ }^{4}$ Department of Veterinary Pathology, Faculty of Veterinary Medicine, Ahmadu Bello University, Zaria, Kaduna, Nigeria
}

\section{Email address:}

drubah2000@yahoo.com (U. S. Azubuike), daveogwu@yahoo.com (O. David), bankwa2006@yahoo.com (R. P. Ibrahim), josephrwuaan@yahoo.com (R. J. Sankey), ije.chibu@yahoo.com (C. I. Chika), sambojames66@gmail.com (S. S. James)

${ }^{*}$ Corresponding author

\section{To cite this article:}

Ubah Simon Azubuike, Ogwu David, Rekwot Peter Ibrahim, Rwuaan Joseph Sankey, Chibuogwu Ijeoma Chika, Sambo Sohnap James. Thyroid Pathology of Cypermethrin and Its Reproductive Implications in Yankasa Rams. International Journal of Biomedical Materials Research. Vol. 4, No. 3, 2016, pp. 43-48. doi: 10.11648/j.ijbmr.20160403.16

Received: October 5, 2016; Accepted: October 29, 2016; Published: December 29, 2016

\begin{abstract}
An investigation into the pathological effects of Cypermethrin on the thyroid gland of Yankasa rams was carried out. Sixteen sexually-mature, healthy Yankasa rams aged 18 - 30 months and weighing between $21.5-46.5 \mathrm{~kg}$ with clinically normal genitalia were used. They were divided equally into two groups (A and B). A served as the treatment group while B served as the control. (A) were given Cypermethrin (3\%) at the dose rate of $3 \mathrm{mg} / \mathrm{kg}(0.1 \mathrm{ml} / \mathrm{kg})$ body weight, topically as pouron. (B)were given distilled water at the same dose rate of $0.1 \mathrm{ml} / \mathrm{kg}$ body weight topically as pour-on. These treatments were repeated every two weeks for a period of 12 weeks. The rams were sacrificed at the end of 12 weeks and the following organs (liver, heart, kidney, brain and thyroid gland), were collected for gross and histopathology. Results showed that no gross pathologic lesions were found on the thyroid gland, theliver, brain and the kidneys of both groups. The heart of the treated group showed petechial hemorrhage. The mean weights of the following organs; liver, thyroid gland, kidneys and heart of the treated and the control groups were $400.00 \pm 0.00 \mathrm{~g}$ and $420.00 \pm 20.0 \mathrm{~g} ; 2.30 \pm 0.37 \mathrm{~g}$ and $1.50 \pm 0.31 \mathrm{~g} ; 70.20 \pm 9.90 \mathrm{~g}$ and $72.60 \pm 3.70 ; 127.51 \pm 46$ and $100.00 \pm 20.00$ respectively. The differences in weight between the two groups were not significantly different $(\mathrm{P}>0.05)$. Histologic sections of the thyroid glands of the treated group showed hyperplasia of the follicular epithelial cells followed by collapsing of the follicles. Histologic sections of the cardiac muscles of the treated group showed focal infiltration of lymphocytes and loss of striations (degeneration). The liver, the kidneysand thebrain (cerebrum) of both groups showed no histologic lesions. It was concluded that Cypermethrin induced thyroid and cardiac pathology in the rams. It was recommended that more investigation be done to unravel the mechanism of inducing thyroid and cardiac pathology in rams.
\end{abstract}

Keywords: Thyroid, Pathology, Cypermethrin, Reproduction, Rams

\section{Introduction}

Cypermethrin is a synthetic pyrethroid insecticide that has been widely used over the past 30 years in China and other countries against pests, particularly Lepidoptera, Cockroaches and termites [1]. It is used primarily in the form of an emulsifiable concentrate, but ultra-low-volume concentrates, wettable powders and joint formulation with other pesticides are available [2]. Technical Cypermethrin varies from a viscous, yellow liquid to a semi-solid crystalline mass at ambient temperature [3]. Cypermethrin is highly stable to light and at temperatures below $220^{\circ} \mathrm{C}$ [3] . Dilute aqueous solutions are subject to photolysis, which occurs at a moderate rate. Cypermethrin has molecular formular of $\mathrm{C}_{22} \mathrm{H}_{19} \mathrm{O}_{3} \mathrm{NCL}_{2}$. The common Trade NamesareAmmo, Avicade, Barricade, CCN 52, Cymbush, 
Folcord, Imperator, Kafil super, Polythrin, Ripcord and Stockade [3].

Cypermethrin is rapidly absorbed from the gastrointestinal tract following oral route of entry. Dermal absorption has been demonstrated in human volunteers. Entry through the eyes is possible in view of dermal exposure although no data is available on that. Parenteral route has been demonstrated, animal toxicity studies have been conducted via both intravenous and intra peritoneal routes [4]. Cypermethrinadministered orally to 6 male volunteers as a single dose of $3.3 \mathrm{mg}$ (cis: trans $1: 1$ ) as a soya oil-based formulation showed that the amount of Cypermethrin absorbed was between $27 \%$ and $57 \%$ (mean $36 \%$ ) of the administered dose. [5]. Cypermethrin administered dermally to 6 male volunteers as a single dose of $31 \mathrm{mg} / 800 \mathrm{~cm}^{2}$ as a soya oil-based formulation (the application site remained unoccluded for $8 \mathrm{~h}$ and was then washed off). The phenoxybenzyl urinary metabolites recovered or absorbed was $0.85-1.8 \%$ (mean 1.2\%) of the administered Cypermethrin [5].

Consistent with the lipophilic nature of Cypermethrin, the highest mean tissue concentrations are found in body fats, skin, liver, kidneys, adrenals and ovaries. Only negligible concentrations are found in the brain [6].

In animals, Cypermethrin has been used as a chemotherapeutic agent against ectoparasite infestation, betaCypermethrin is a mixture of the alpha and theta forms of the insecticide. Although Cypermethrin was considered safe and was widely used on agricultural crops and forests as well as in public and animal health, there is accumulating evidence that chronic exposure or high-dose of Cypermethrin has toxic effects on humans and animals [1]. Cypermethrin can be found in trace amounts or at higher concentrations in soil and air [1]. In mammals, Cypermethrin can accumulate in body fat, skin, liver, kidneys, adrenal glands, ovaries, lung, blood and heart. However, the main target for Cypermethrin is the central nervous system [1]. The absorption and elimination of Cypermethrin is reported as rapid in the different mammalian species tested [6]. The oral $\mathrm{LD}_{50}$ for the rat ranged from 200 $400 \mathrm{mg} / \mathrm{kg}$ body weight, short term and long-term toxicity studies on rats, mice, and dogs have shown effects on growth, the liver and kidneys, the nervous system and the blood [6]. This work was designed to investigate the gross and histopathological effects of Cypermethrin on the thyroid gland of Yankasa rams.

\section{Materials and Methods}

\subsection{Study Location}

The research was carried out at the National Animal Production Research Institute (NAPRI) Shika, Ahmadu Bello University Zaria, which is situated in the Northern Guinea Savannah and lying between latitudes $11^{\circ}$ and $12^{\circ} \mathrm{N}$ and longitude $7^{\circ}$ and $8^{\circ} \mathrm{E}$, at an elevation of $650 \mathrm{~m}$ above sea level. The area has an annual rainfall of $1100 \mathrm{~mm}$. (7). There are two seasons r rainy season (May-October) and dry season
(November-April)\} (8).

\subsection{Experimental Animals}

The animal experiments followed the principles of the Laboratory animal care (9). Sixteen sexually-mature, healthy Yankasa rams aged 18 - 30 months and weighing between $21.5-46.5 \mathrm{~kg}$ with clinically normal genitalia were used. The rams were purchased from the open market in Sabua Local Government Area of Katsina State. They were acclimatized for two weeks at the Small Ruminant Research Programme Experimental Unit of NAPRI, after which they were judged to be in good health based on clinical findings, hematological and faecal examinations. They were housed at the Small Ruminant Research Programme Experimental Unit of NAPRI. The house was made of brick concrete pens with concrete floors. The rams were divided into two groups of eight each. They were given concentrate feedad- libitum (cotton seed, maize offal, maize, wheat offal, bone meal and salt) in the morning and later in the evening; hay was made available during the day at intervals. The hay used was Digitariasimuthii, and water was given ad-libitum.

\subsection{Experimental Design and Treatment}

The 16 rams were divided equally into two groups (A and B) Group A served as the treatment group while group B served as the control. The animals were acclimatized for two weeks during which time blood and faecal samples were collected and analyzed for haemoparasites and helminths and treatments given where necessary.

Administration of 3\% Cypermethrin

The rams in group (A) were given Cypermethrin (3\%) at the dose rate of $3 \mathrm{mg} / \mathrm{kg}(0.1 \mathrm{ml} / \mathrm{kg})$ body weight, topically as pour-on. The control group (B) rams were given distilled water at the same dose rate of $0.1 \mathrm{ml} / \mathrm{kg}$ body weight topically as pour-on. These treatments were repeated every two weeks for a period of 12 weeks.

\subsection{Sample Collection and Analysis}

The rams were sacrificed at the end of 12 weeks and the following organs(liver, heart, kidney, brain and thyroid), were collected for gross and histopathology.

\subsubsection{Gross and Histopathological Examination}

Four rams each from groups A and B were sacrificed and the following organs (thyroid, liver, kidney, brain and heart) were removed by dissection from all the rams and photographs were taken. The, liver,kidney, heart and thyroid gland were weighed and stored in $10 \%$ formalin for histopathology. The brain and the pituitary, were gently removed from the cranial cavity and properly cleaned off the meninges [10]. The brain was then immersed in $10 \%$ formalin for 24 hours and later transferred to Bouins' solution and kept for at least 2 - 3 weeks, the pituitary was dissected out and a section of the cerebrum was cut for gross and histopathology. Pathological lesions were noted immediately after dissection from the rams and photographs were taken. 


\subsubsection{Histological Procedure}

Routine H \& E (Haematoxylen and Eosin) staining method (general method) was used. The fixed tissues were trimmed and placed in the plastic or metal capsules with labels. They were dehydrated through series of graded alcohols $(70 \%$, $80 \%, 90 \%, 95 \%$ and $100 \%)$ and cleared in xylene and then infiltrated with molten paraffin wax. Sections $(5-6 \mu \mathrm{m})$ microns thick were cut from embedded tissue using Jung Rotary Microtome (Model 42339). The tissues were mounted on clean, grease free glass slides stained with Hematoxylin and Eosin $(\mathrm{H} \& \mathrm{E})$ as standard procedure at room temperature. The prepared slides were studied using binocular light microscope (Olympus Binocular Microscope). At the Histopathology Laboratory of the Department of Veterinary Pathology, Faculty of Veterinary Medicine, Ahmadu Bello University, Zaria. Photomicrographs were captured, labeled and documented.

\subsection{Statistical Analysis of Data}

Data were expressed as means and Standard Error of Mean (SEM). Data wereanalysed using paired student's t-test with SPSS/PC computer program (Version 20.0, SPSS ${ }^{\circledR}$, Chicago IL, USA). Differences with confidence values of $p<0.05$ were considered statistically significant (11).

\section{Result}

\subsection{Gross Pathology}

No gross pathologic lesions were found on the thyroid gland,theliver, brain and the kidneys of the treated and control groups. The heart of the treated group showed petechial hemorrhage (Fig. 2) while the control group showed no gross lesions (Fig. 1). The mean weights of the following organs; liver, thyroid gland, kidneys, heart of the treated and the control groups are presented (Table 1). The mean weight of the thyroid gland and the heart of the treated rams were higher than in the control rams. The differences in weight between the treated and control groups were not significantly different $(\mathrm{P}>0.05)$.

Table 1. Live weight of rams during sacrifice, weights of thyroid gland, liver, kidney and heart of both the treated and controlrams. (Mean \pm SEM).

\begin{tabular}{lll}
\hline \multirow{2}{*}{ Parameters } & Treated & Control \\
\cline { 2 - 3 } & $\mathbf{n}=\mathbf{4}$ & $\mathbf{n}=\mathbf{4}$ \\
\hline Live weight $(\mathrm{kg})$ & $29.80 \pm 1.40$ & $26.30 \pm 1.30$ \\
Thyroid weight $(\mathrm{g})$ & $2.30 \pm 0.37$ & $1.50 \pm 0.31$ \\
Liver weight $(\mathrm{g})$ & $400.00 \pm 0.00$ & $420.00 \pm 20.00$ \\
Kidney weight $(\mathrm{g})$ & $70.20 \pm 9.9$ & $72.60 \pm 3.70$ \\
Heart weight $(\mathrm{g})$ & $127.51 \pm 46$ & $100.00 \pm 20.00$ \\
\hline
\end{tabular}

\subsection{Histopathology}

Histologic sections of the thyroid glands of the control group had normal follicular epithelial cells (Fig. 3), while that of the treated group showed hyperplasia of the follicular epithelial cells followed by collapsing of the follicles. This type of reaction is typical of stimulation with Thyroid Stimulating Hormone (TSH) (Fig. 4). Histologic sections of the cardiac muscles of the control group showed no lesions (Fig. 5) whereas histologic sections of the cardiac muscles of the treated group showed focal infiltration of lymphocytes and loss of striations (degeneration) (Fig. 6). Histologic sections of the liver of the control group showed no lesions. Similarly, the treated group showed no lesions. Histologic sections of the kidneys of the control group showed no lesions. The cortex showed a good amount or number of glomeruli, half of which contained fluid in the urinary space and extending into the lumen of the proximal convoluted tubules. Similarly, the histologic sections of the kidneys of the treated group showed no lesions. The cortex showed a good amount or number of glomeruli, half of which contained fluid in the urinary space and extending into the lumen of the proximal convoluted tubules. Histologic sections of the brain (cerebrum) of the control group showed no lesions, sections of the brain of the treated group showed no lesions.

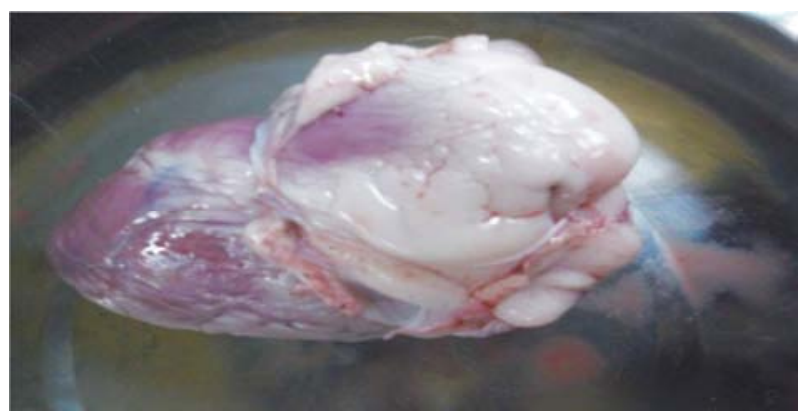

Figure 1. Photographof the heart of control group: showing no gross lesions.

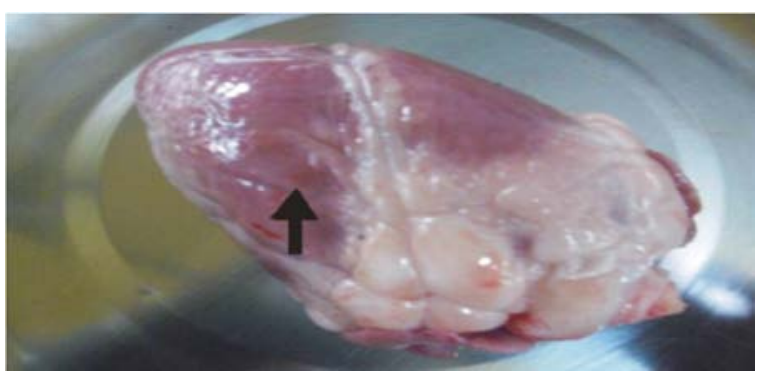

Figure 2. Photograph of the heart of treated group showing petechial haemorrhage.

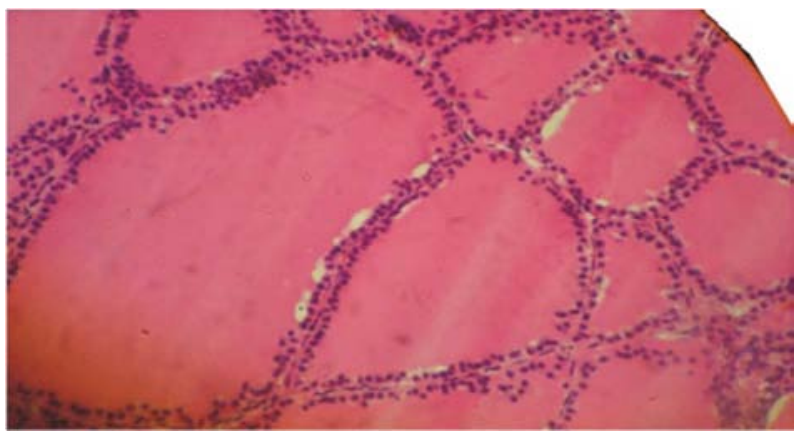

Figure 3. Photomicrograph of Thyroid gland of control group: with normal follicular epithelial cells (x400) (H\&E) stain. 


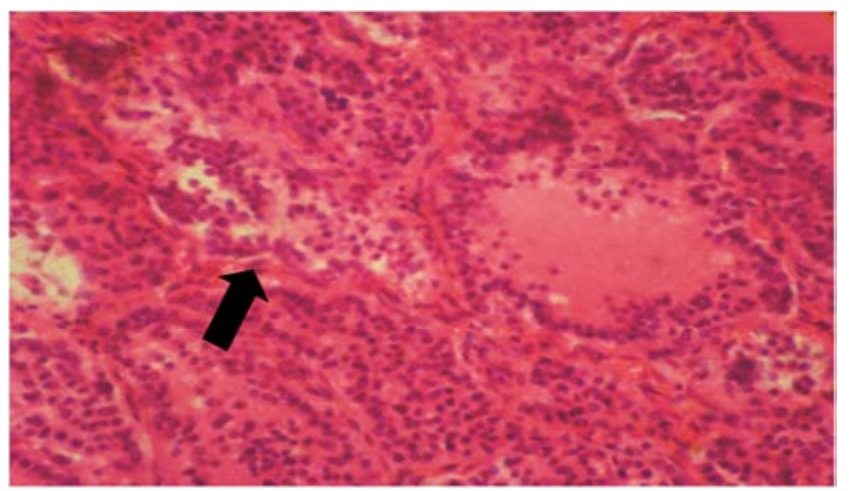

Figure 4. Photomicrograph of Thyroid gland of treated group: showing hyperplasia of the follicular epithelial cells followed by collapsing of the follicles. This type of reaction is typical of stimulation with TSH (x400) (H\&E) stain.

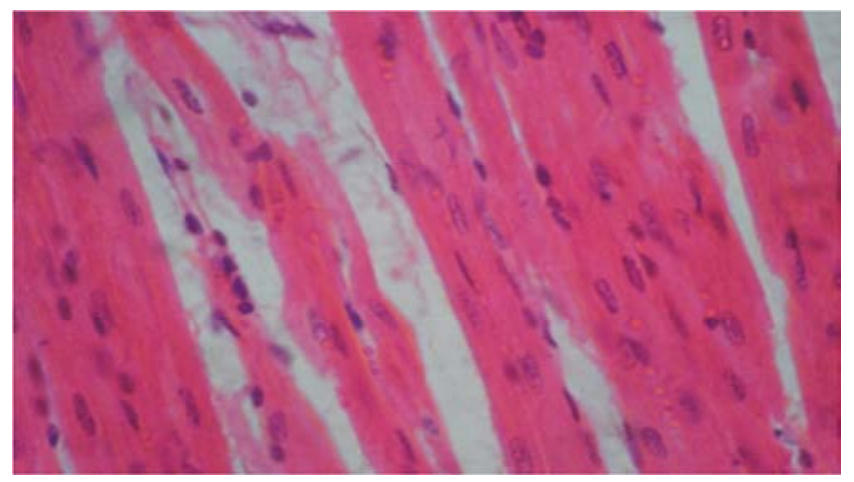

Figure 5. Photomicrograph of Cardiac muscle of control group: no lesions found (x400) (H\& E) stain.

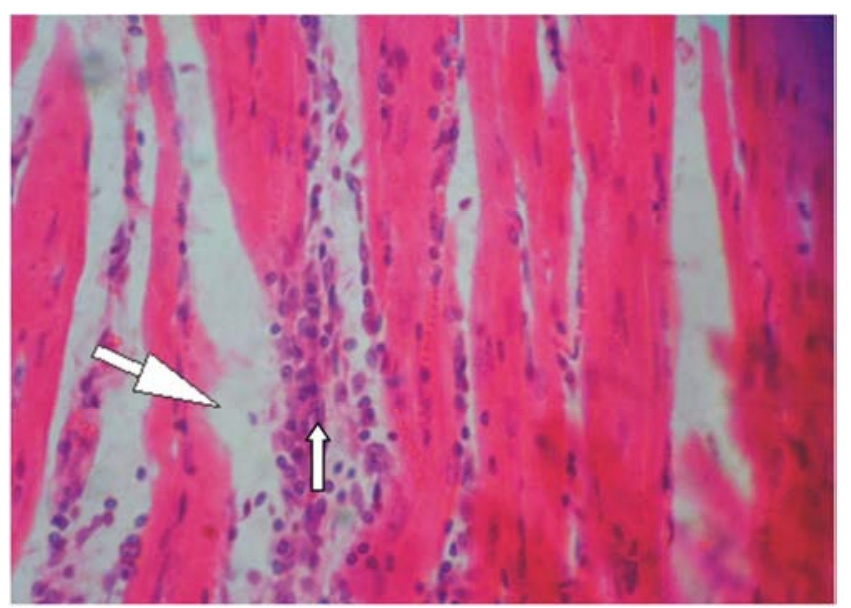

Figure 6. Photomicrograph of Cardiac muscle of treated group: showing focal infiltrations of lymphocytes and loss of striations (degenerations) (x400) $(H \& E)$ stain.

\section{Discussion}

Pyrethroids are rapidly metabolized in mammals and several studies have shown that Cypermethrin damages the brain, liver and erythrocytes by causing oxidative stress [1]. Gross pathological observations of the organs examined in this study revealed that the heart was the major organ affected by low dose Cypermethrin in rams. The heart of treated rams showed petechial hemorrhage, other organs examined were the liver, brain (cerebrum), kidney and thyroid gland. The weights of these organs did not show any significant differences. These findings vary from the report of WHO, 1989b [6]. Short-term and long-term toxicity studies on rats, mice and dogs have shown effects on growth, the liver, kidneys, the nervous system and the blood [6]. Longterm feeding studies with laboratory animals have shown that Cypermethrin causes adverse effects [12]. In rats, it caused reduced growth rate and increased liver weight. In mice, it caused reduced weight gain, mild anemia and increased liver weight [12]. In dogs it caused loss of appetite, incoordination and tremors. In rabbits, it caused pathological changes in the thymus, liver, adrenal glands, lungs and skin [12]). These disagreement with our studies is very likely to be due to the route of administration and probably the dose used. Marked differences in the urinary metabolite profile by oral and dermal routes in human volunteer studies suggest that Cypermethrin could be significantly metabolized in the skins before systemic circulation occurs [5]. Topical application of Cypermethrin may have gone a long way in reducing the adverse effects it could have on these organs. Nevertheless, the heart was affected. In anotherperspective, Cypermethrin may have different target organs in different species. The differences in pyrethroid potency between species have been attributed to differences in the sensitivity of VSSCs (voltage sensitive sodium channel) to these compounds, body temperature and metabolism [13].

Histologically, of all the organs accessed, interesting findings were made in the heart and the thyroid glands. The histologic observation in the heart showed focal infiltration of lymphocytes and loss of striations (degeneration). This observation was a reflection of the gross lesion found on the heart which indicates that the heart may be one of the major target organs of Cypermethrin in rams. The thyroid glands revealed hyperplasia of the follicular epithelial cells followed by collapsing of the follicles. This type of reaction is typical of stimulation with thyroid stimulating hormone (TSH). The anatomical relationship between the gonadotropic releasing hormone and the thyrotropin releasing hormone production site in the brain may be responsible for this effect. The axons of the hypophysiotrophic hypothalamic nuclei terminate in the external zone of the median eminence, where it establishes neurovascular contacts with the primary capillaries of the hypophyseal portal system. In this zone, chemical transmitter substances, so called releasing hormones. $(\mathrm{CRH}=$ corticotrophin releasing hormone; GnRH = gonadotropin releasing hormone), are discharged into the capillaries and reach the adenohypophysis via the portal veins [11]. The adenohypophysis, pars distalis consists of clusters and cords of cells in close apposition to a dense network of capillaries (Sinusoids). The characteristic of the cells of the pars distalis include basophilic cells and these are $\mathrm{TSH}=$ thyroid stimulating hormone, $\mathrm{FSH}=$ follicle stimulating hormone and $\mathrm{LH}$ or ICSH = luteinizing hormone or interstitial cell - stimulating hormone [10]. Thyrotropin acts almost exclusively on the thyroid gland where it induces a series of events leading to synthesis and release of thyroxin. 
In male animals synthesis and release of androgen depend on the presence of luteinizing hormone (ICSH or LH) [11]. FSH and LH are regulated by gonadal steroids. Testosterone, via aromatization to estrogen, maintains libido and exerts a negative feedback on the hypothalamus regulating FSH and LH secretions. [15]. FSH is also regulated by inhibin in the males. Dosing of adult male NMRI mice for 35 consecutive days with Cypermethrin decreased sexual behaviours (sniffing, following, mounting and coupling). However, continued treatment with Cypermethrin lowered circulating testosterone levels significantly and increased the serum FSH and LH levels [16].

Treatment of rats with Cypermethrin at doses of 18.93 or $39.66 \mathrm{mg} / \mathrm{kg}$ per day decreased FSH and LH levels as well as testosterone levels. However treatment with lower doses of Cypermethrin decreased serum testosterone levels while increasing serum LH and FSH levels [16]. Elevated levels of FSH and LH can result from the direct effects of pyrethroid on the CNS or they can be in response to decreased testosterone by negative feedback of the anterior pituitary.

The point here is that low dose of Cypermethrin $3 \mathrm{mg} / \mathrm{kg}$ body weight may exert influence on TSH and FSH, considering the anatomical relationships. Low serum testosterone exert positive feedback directly on the hypothalamus to cause, release of the releasing hormones via the portal vein. Also histologically FSH, LH and TSH which are cells of the pars distalis belong to the basophilic group and are all glycoproteins. The effect of Cypermethrin on the thyroid gland of the treated rams may be mediated through direct effect on the CNS. Cypermethrin exposed rams may sustain a nonspecific stimulation of the purple amphophils (FSH cells) and red amphophil (LH cells). A similar effect will be exerted on related cells i.e. cyanophil (TSH cells) or even further to protein hormone acidophilic cells: Aurantiphil (STH cells) somatotrophic hormone and erythrophil (LTH cells) luteotropic hormone (rat) or lactogenic hormone. It may also be extended to the third group of cells of the pars distalis which are chromophobic cells (ACTH) adrenocorticotropic hormone. Another possibility is the lipophilic nature of Cypermethrin, which is found in highest amount in the body fat. Presence of Cypermethrin in body fat may induce TSH. TSH causes a release of free fatty acids from adipose tissue. Associated with an increased blood flow, after administration of TSH, is an increase in the protein, carbohydrate, lipid and salt metabolism of the thyroid gland [13]. The exact mechanism through which Cypermethrin induced thyroid and cardiac pathologies in the present studies, calls for further investigation.

\section{Conclusion}

The conclusion was that $3 \mathrm{mg} / \mathrm{kg}$ given forthnightly for twelve weeks elicited thyroid pathology, as well as cardiac degeneration in Yankasa rams. The species of animals involved, the dose of Cypermethrin used and the rout of administration of the drug (dermal) may be playing key roles in determining the organs affected and severity of toxicity.
Thyroid pathology may have huge reproductive implications in Yankasa rams. It was therefore recommended that further studies be done to unravel the mechanism through which Cypermethrin causes thyroid pathology.

\section{References}

[1] Wang, X-Z., Liu, S-S., Sun., Wu, J-Y., Zhou, Y-L and Zhang, J-H. (2009). $\beta$ - Cypermethrin impairs reproductive function in male mice by inducing oxidative stress. Theriogenology, 72, 599-611.

[2] Inchem. (1989a). Joint meeting of the FAO Panels of experts on pesticide residues Rome; and the environmental and the WHO expert group on pesticide residues Rome; http//www.inchem.org.Accessed 8/3/2010.

[3] Inchem. (1989b). IPCS: International programme on chemical safety: Health and Safety guide No. 22, a companion volume to environmental health criteria 82: Cypermethrin. World Health Organization for the international programme on chemical safety.

http://www.inchem.org/documents/hsg/hsg022.html.accessed8 $/ 3 / 2010$.

[4] Rita, F. (1996). Cypermethrin (PIM 163). IPCS Inchem. London Poison Unit. http://www.inchem.org/documents/plms/chemical/plm163.htm 1. Accessed 10/28/2011.

[5] Woolen, B. H., Marsh, J. R., Laird, W. S. D and Lesser, J. E. (1992). The metabolism of Cypermethrin in man: Differences in urinary metabolite profiles following oral and dermal administration. Xenobiotica, 22(8): 983-991.

[6] WHO. (1989b). Cypermethrin environmental health criteria 82. Geneva Switzerland; United Nations Environment Programme, International Labor organization and WHO. Health and Safety Guide No 22. http://www.inchem.org/documents/hsg/hsg022.htm. Accessed $8 / 3 / 2010$

[7] Igono, M., Molokwu, E. C. I and Aliu, Y. O. (1982). Body temperature responses of Savanah Brown goats to hamattan and hot-dry seasons. International Journal ofBiometeorology, 26: $225-230$.

[8] Ubah, S. A., Ogwu, D., Rekwot, P. I., Rwuaan, J. S and Chibuogwu, I. C (2016). Gonadal and epididymal sperm reserves of Yankasa rams treated with Cypermethrin. American Journal of Biomedical and Life Sciences 4(2) pp1620.

[9] Canadian Council on Animal Care Guide (CACC). http://www.ccac.ca/Documents/Standards/Guidlines/Experime ntal_Animals_Voll.pdf (second ed.) 1993. Accessed $04 . \overline{1} 1.2015, \overline{0} \mathrm{pm}$.

[10] Harper, J. W. and Maser, J. D. (1975). A macroscopic study of the brain of bison,theAmerican plain buffalo. Anatomical Record, 18:187-202.

[11] Daniel, W. W. (1991). Analysis of variance. In: Daniel, W. W. (Ed), Biostatistic: AFoundation for Analysis in the Health Sciences. John Wiley \& Sons, Hoboken. Pp. 74-320.

[12] Caroline, C. (1996). Insecticide fact sheet. Journal of Pesticide Reform/Summer Vol. 16, No 2. Pp. 1-20. 
[13] Wolansky, M. J and Harrill, J. A. (2007). Neurobehavioral toxicology of pyrethroidinsecticide in adult animals: A critical review. Neurotoxicology and Teratology, 89: 271-277.

[14] Delman, H and Brown, E. M. (1976). Textbook of Veterinary Histology. Lea and Febiger. Pp. 290-317, 376-387.

[15] Timothy, J. P. (2009). Normal reproduction in male animals.
In: David, E. N., Timothy, J. P and Garry, C. W (Ed). Veterinary Reproduction and Obstetrics $9^{\text {th }}$ Ed. Saunders Elsevier. Pp. 681-759.

[16] Jalal, S., Ramin, H and Roohollah, T. Z. (2010). Effect of Cypermethrin on sexual behaviour and plasma concentrations of pituitary gonadal hormones. InternationalJournal of Fertility and Sterility Vol. 4, No. 1, Pp. 23-28. 